\title{
Entre o consultório e o terreiro: mediações, ruídos e silenciamentos nos itinerários terapêuticos de adeptos do candomblé
}

\author{
Between the physician"s office and the "terreiro": mediations, noises \\ and silences in the therapeutic itineraries of "candomblé" followers
Entre la oficina y el "terreiro": mediaciones, sonidos y silencios en los itinerarios terapéuticos de los adeptos de "candomblé"

\author{
Clarice Moreira Portugal | clariceportugal@gmail.com \\ Universidade Federal da Bahia, Programa de Pós-Graduação em Saúde Coletiva. Salvador, Bahia, Brasil.
}

\begin{abstract}
Resumo
O presente artigo tem por objetivo discutir os aspectos infocomunicacionais concernentes à relação que adeptos do candomblé estabelecem com serviços de saúde públicos e privados. A metodologia centrouse na realização de onze entrevistas semiestruturadas com iniciados e não-iniciados (mas participantes do terreiro), baseadas na aplicação do instrumento McGill MINI Narrativa de Adoecimento. Os dados coletados foram submetidos à análise de conteúdo. Verificaram-se significativa valorização dos serviços médicos e formas peculiares de apropriação do discurso dos especialistas por parte dos entrevistados. No entanto, sua busca por atendimento nesses espaços é marcada por relações por vezes negligentes e que menosprezam o sofrimento descrito pelo usuário e sua perspectiva religiosa. Assim, parece importante abrir condições de possibilidade para que essa dimensão seja abordada não como um diagnóstico, mas como um fator intrínseco à experiência de sofrimento, que deve ser alvo de reconhecimento por parte do profissional de saúde.
\end{abstract}

Palavras-chave: Candomblé; Religião e ciência; Saúde Coletiva; Cobertura de serviços de saúde; Relação médico-paciente; Entrevista; Conhecimento; Itinerário terapêutico.

\begin{abstract}
This paper aims to discuss the infocommunicational aspects related to "candomblé" " followers in their relation with health services, both public and private. The methodology was focused on eleven semi-structured interviews of initiated and not initiated people (but who takes part in "terreiro") based on the instrument McGill MINI Narrativa de Adoecimento (McGill Narrative of Illness - MINI). The collected data were submitted to content analysis. It was verified significant value given by the interviewees to the medical services and peculiar modes of appropriation of the specialist discourse, but the search for health care sometimes is characterized by negligence and a double underestimate: of people's suffering and their religious perspective. This religious dimension must be treated not as a diagnosis, but as an important fact inherent to the suffering experience. So, it is supposed to be recognized by the health professionals.
\end{abstract}

Keywords: "Candomblé”; Religion and science; Public health; Health service coverage; Physician-pacient relationship; Interview; Knowledge; Therapeutic itinerary. 


\section{Resumen}

Este artículo tiene como objectivo discutir los aspectos infocomunicacionales sobre la relación de "candomblé" establecida con los servicios de salud públicos y privados. La metodología se centró en la realización de once entrevistas semiestructuradas con iniciados y no iniciados (pero participantes del "terreiro"), basada en la aplicación del instrumento McGill MINI Narrativa de Adoecimento (McGill Narrative of Illness - MINI). Los datos obtenidos fueron sometidos a un análisis de contenido. Los entrevistados valorizan los servicios médicos y tienen peculiares formas de apropiación del discurso de los especialistas. Sin embargo, la búsqueda de atención en estos espacios está marcada por las relaciones a veces negligentes y que menosprecian el sufrimiento descrito por el usuario y su perspectiva religiosa. Por lo que parece importante abrir condiciones de posibilidad para que esta dimensión seja abordada no como un diagnóstico, sino como un factor intrínseco a la experiencia del sufrimiento, que debe ser objecto de reconocimiento por parte del profesional de la salud.

Palabras clave: "Candomblé"; Religión y ciencia; Salud pública; Cobertura de los servicios de salud; Relación médico-paciente; Entrevista; Conocimiento; Itinerario terapéutico.

Declaração de conflito de interesses: A autora declara não haver conflitos de interesse de qualquer espécie na realização da pesquisa. Fontes de financiamento: Coordenação de Aperfeiçoamento de Pessoal de Nível Superior (Capes)

Considerações éticas: Comitê de Ética em Pesquisa da ENSP/Fiocruz, sob protocolo no 028779/2013. Aprovado em 23 de maio de 2013. CAAE: 14752113.5.0000.5241.

Agradecimento/Contribuições adicionais: Agradecemos à Capes pelo apoio ao projeto e a todas as pessoas que se dispuseram a participar da pesquisa.

Histórico do artigo: Submetido: 15.abr.2015 | Aceito: 01.dez.2015 | Publicado: 30.mar.2016

Apresentação anterior: Os dados apresentados no artigo fazem parte da dissertação de mestrado da autora intitulada "Da linguagem dos infortúnios às narrativas de doença: o sofrimento psíquico e a construção de itinerários terapêuticos entre adeptos do candomblé", defendida no Programa de Pós-Graduação em Informação e Comunicação em Saúde (PPGICS/ Icict/ Fiocruz) no dia 28 de janeiro de 2014. Disponível em: http://arca.icict.fiocruz.br/handle/icict/8543

Licença: CC BY-NC atribuição não comercial. Com essa licença é permitido acessar, baixar (download), copiar, imprimir, compartilhar, reutilizar e distribuir os artigos, desde que para uso não comercial e com a citação da fonte, conferindo os devidos créditos de autoria e menção à Reciis. Nesses casos, nenhuma permissão é necessária por parte dos autores ou dos editores 


\section{Introdução}

A inserção de sujeitos no candomblé muito frequentemente é precedida por um momento de crise no curso de suas trajetórias existenciais. Esse período pode se caracterizar tanto por problemas geradores de sofrimento de ordem pessoal, afetiva, financeira, etc., quanto pelo adoecimento físico e/ou mental. Tal constatação é referida por diversos autores no âmbito da antropologia (médica e social) e da saúde coletiva $^{1-4}$.

Quando se utiliza o termo candomblé, pode-se estar falando da religião em si, mas também das cerimônias ou do lugar onde ocorrem práticas religiosas. De maneira geral, é possível compreendê-lo como um conjunto de crenças que se preservaram e se disseminaram nas diversas regiões do Brasil com a influência de diversas etnias africanas ${ }^{5}$.

A questão do silenciamento dos adeptos de cultos afro-brasileiros no Sistema Único de Saúde (SUS) no que se refere às suas crenças mostra-se aqui pertinente. $\mathrm{O}$ acesso às ações e serviços por parte da população negra e de religiões de matrizes africanas ainda é prejudicado. Entre as principais causas para tal, encontram-se: o preconceito, o racismo cordial e a intolerância religiosa ${ }^{6}$, que colaborariam para o seu estatuto de invisibilidade. Com relação a isto, observa-se que a discriminação, seja de cunho étnico ou religioso, nos serviços de saúde repercute significativamente sobre as ações em saúde em termos materiais e simbólicos, concorrendo para ações iatrogênicas.

O desinteresse por parte dos médicos e profissionais dos serviços de saúde pelas práticas alternativas de cuidado - onde se situaria a religiosidade - das quais se valem seus pacientes mostra-se como um problema, na medida em que, por isso, os próprios sujeitos evitam falar sobre elas no sistema oficial7. Koenig8 ${ }^{8}$ destaca a importância da construção de uma dita "história espiritual" que permita explorar essa dimensão, de maneira a compreender em que medida ela interfere em seu sofrimento; considerando os processos a ele intrínsecos desencadeados por instituições corporativas e mídias com discursos e ações depreciativos frente a estas práticas 9.

Dessa forma, este artigo tem por objetivo discorrer acerca dos aspectos infocomunicacionais concernentes à relação que adeptos de religiões de matrizes africanas - em especial do candomblé - estabelecem com serviços de saúde, tanto os públicos quanto os privados. Tendo como base um trabalho de pesquisa teórico e empírico do qual derivou a dissertação de mestrado da autora ${ }^{10}$, serão destacados alguns aspectos centrais, a saber: a centralidade do saber (bio)médico e o silenciamento do usuário adepto dessa religião no encontro com o profissional de saúde; a desconsideração do sofrimento desses sujeitos a partir das categorias "não ter nada" e "ser/estar desenganado"; e os problemas no estabelecimento de uma rede de cuidado, seja entre especialistas clínicos, seja destes com tais espaços religiosos, o que se concretizaria nos processos de revolving door e negligência nos atendimentos.

\section{Itinerários terapêuticos, informação e saúde: aspectos teórico-conceituais}

A busca por cuidado, a construção e adesão a um dado projeto terapêutico de modo algum se restringem à esfera dos serviços de saúde em uma acepção estrita. Ao contrário, existe todo um conjunto de significados compartilhados socialmente que engendram experiências idiossincráticas (individuais e coletivas) no que se refere ao adoecer.

A interpretação do itinerário terapêutico está atrelada à rememoração de eventos e a experiências anteriores que são evocadas, reorganizadas e ressignificadas. Por meio da narrativa, trazem-se à cena opções, negociações, pactos e processos decisórios que conduziram a um conjunto específico de ações, tornando-se possível reconstruir essa trajetória. Nesse processo, o itinerário torna-se uma unidade articulada quando o ator tenta interpretar suas experiências passadas de acordo com suas circunstâncias atuais ${ }^{11}$. A elaboração 
do itinerário terapêutico, nessa conjuntura, abarca necessariamente a arena de possibilidades socioculturais que subjazem à elaboração e incremento de projetos terapêuticos, o que abre espaço para a contradição e toda uma linhagem de paradoxos e decisões por vezes aparentemente incoerentes.

Está em jogo na sua construção toda uma série de escolhas, barganhas, modos de compreender e lidar com o sofrimento nunca dados de antemão ${ }^{12}$. As escolhas por certas opções terapêuticas em detrimento ou em complementaridade a outras envolvem toda uma arena de negociações e modificações ${ }^{13}$. Recorrer, portanto, a diferentes (e mesmo antagônicos) recursos na construção do itinerário terapêutico é algo bastante comum ${ }^{14}$.

Visões e decisões contraditórias e afins mesclam-se e distinguem-se nessa disputa semântica que, por seu turno, ressalta o caráter experiencial e intersubjetivo do famigerado processo saúde-doença. As definições de situação, bem como a natureza das relações intersubjetivas envolvidas no processo de tomada de decisão são aspectos fundamentais a serem considerados na construção do itinerário terapêutico, o qual inclui todo um contexto atravessado por instituições, representações coletivas e relações sociais que os indivíduos reinterpretam e recompõem em função das situações e restrições existentes ${ }^{15}$. Por isso, ao abordá-lo, é preciso que se leve em conta a diversidade de possibilidades de cuidado (in)disponíveis, bem como as relações envolvidas nos processos de tomada de decisão.

Kleinman ${ }^{16}$ considera que o percurso de busca por cuidado não se restringe aos serviços e instituições de saúde prestigiadas por fundarem suas ações de cuidado em um conhecimento científico, mas atravessa os subsistemas familiar, profissional e popular, situando-se neste último os atores e instituições religiosos. Por esse raciocínio, seria possível perceber a existência de setores com capacidade de interação nos sistemas de saúde locais ${ }^{17}$. Os sistemas de saúde congregam ideias e noções acerca das causas de adoecimentos e de seus tratamentos, trazendo em seu bojo a miríade de aspectos culturais que expressam a resposta social diante das necessidades de saúde. Dentro dele diversos setores com suas respectivas práticas, conceitos e saberes interagem entre si, estabelecendo relações de cooperação e competição.

Quando se fala aqui de saber, considera-se que ele possui uma maior profundidade, apreensão e sistematização de sentidos e aprendizados, cuja sedimentação permitiria uma abertura e construção coletiva. O saber encontrar-se-ia entre o interno e o externo, envolvendo instituições, coletivos e grupos por meio da troca de experiências, práticas, documentos, etc.

Os saberes encontram-se em trânsito permanente no e entre os diversos espaços sociais, onde são apropriados e transformados; atravessam e configuram "zonas de mediação" por onde se dá o complexo circuito de produção e apropriação social das informaçõe ${ }^{18}$. Dessa forma, não é possível pensar nas ditas "práticas infocomunicacionais" como algo neutro. Ao contrário, possuem uma dimensão política ${ }^{19}$ que lhes define e posiciona os atores envolvidos no processo.

De maneira geral, o setor que ocupa o lugar de referência quanto aos demais é o dito setor oficial calcado na práxis e no arcabouço teórico da biomedicina. Envolvendo-o e ultrapassando-o, contudo, encontram-se outros sistemas e suas respectivas bagagens de saberes e conhecimentos, que interagem entre si aos moldes da elaboração de um terceiro conhecimento, com especial destaque para o subsistema familiar que tem uma função especialmente mediadora em relação aos demais.

Profundamente ligado à ação social, o terceiro conhecimento encontra-se conectado aos meios de produção, apropriação e disseminação de informações, como também aos seus usos e é constantemente aberto à gênese de sentidos e mediações; e é justamente desse caráter intersticial que provém sua terceiridade ${ }^{20-21}$. Marteleto, Ribeiro e Guimarães frisam que "as formas de conhecimento cotidiano, implícitas nos sentimentos e habilidades da população e na vivência prática dos seus problemas, deveriam ser levadas em conta, juntamente com o conhecimento profissional médico”22

O adoecer, por essa lógica, comporta circuitos de troca e construção do conhecimento, dado que a doença, a procura por cuidado e a elaboração de um projeto terapêutico, assim com as expectativas que 
decorrem desse processo, constroem-se apenas no contexto relacional. Quando se está diante de uma experiência de doença - como protagonista ou não -, encontra-se todo um arcabouço de conceitos, definições e saberes; e a abertura desse "novo mundo" é, como o é a própria experiência de doença, algo íntimo e coletivo, situando-se no domínio do "entre". Está em jogo aqui um conhecimento, fruto de uma construção compartilhada ${ }^{23}$, realizado de modo colaborativo e cuja concretude se submete a (in)constantes possibilidades de reformulação.

Posto esse referencial, serão exploradas agora algumas dimensões importantes relacionadas ao fluxo de busca - no sentido de que sejam consideradas as mudanças de direção e intensidade - por cuidado e remissão do sofrimento em serviços de saúde e terreiros de candomblé.

\section{Metodologia}

Como fonte inicial de obtenção das narrativas de doença, optou-se aqui pela realização de entrevistas semiestruturadas com iniciados e pessoas inseridas em casas de santo como abians, ou seja, não iniciados, mas que estão deliberando acerca de sua iniciação.

O recrutamento de sujeitos foi definido pela técnica snowball sampling ("amostragem bola de neve"). Esta metodologia utiliza cadeias de referência e consiste na indicação de novos participantes pelos sujeitos recrutados inicialmente, até que seja alcançado o "ponto de saturação", definido a partir da repetição dos conteúdos das entrevistas, sem acréscimo de novas informações relevantes à pesquisa ${ }^{24}$. Para a sua delimitação, foram necessárias incontáveis idas e vindas às transcrições conjugadas às observações e registros contidos nos relatos de campo, de modo que fosse possível examinar o material empírico e perceber se este já possuía a densidade necessária ao cumprimento dos objetivos propostos ${ }^{25}$.A partir desse norte, foram realizadas onze entrevistas: quatro com abians e sete com pessoas já iniciadas.

As entrevistas tiveram como eixo de investigação a experiência de sofrimento, a busca por cuidado na casa de candomblé e a (re)construção do itinerário terapêutico dos sujeitos. Para tal, foi selecionada a versão traduzida e adaptada para o Brasil do roteiro de entrevista McGill-Groleau (McGill Ilness Narrative Interview - MINI), que tem por objetivo elicitar narrativas de doença em pesquisa em saúde ${ }^{26}$. Desenvolvido pelo grupo de pesquisa em Psiquiatria Social e Transcultural da Universidade McGill localizada em Montreal, Canadá, esse modelo de entrevista narrativa foi traduzido para português e adaptado para o Brasil em 2007 pelo grupo de pesquisa liderado pelos Profs. Drs. Erotildes Leal, Alicia Navarro de Souza e Octavio Serpa no Instituto de Psiquiatria da Universidade do Brasil (IPUB/ UFRJ)i.

Esste roteiro é composto de cinco blocos: três fundamentais e dois suplementares. No trabalho que deu origem a este artigo, a entrevista foi realizada no seu formato integral, que envolve os segmentos expostos a seguir:

1. Narrativa sobre o sintoma e a experiência inicial de doença, organizada a partir da contiguidade dos eventos;

2. Protótipos relacionados a problemas de saúde com base na experiência prévia do entrevistado, enfocando as semelhanças, diferenças e a descrição do processo de individuação do problema;

3. Modelos explicativos, atribuições causais, expectativas concernentes ao tratamento, curso e prognóstico;

4. Serviços (instituições, locais de atendimento, etc.) e resposta ao tratamento neles obtidos;

5. Impacto sobre a vida: incluem-se aqui aspectos relacionados a valores e às vicissitudes de viver com o problema de saúde em questão.

i Versão reconhecida pela Universidade McGill e disponível no site para download. http://www.mcgill.ca/tcpsych/research/cmhru/mini 
Anteriormente à aplicação do MINI, na medida em que os participantes não necessariamente se reconheciam como pacientes, foi utilizada uma vinheta introdutória no início da entrevista (impressa e lida junto com o entrevistado), com o intuito de introduzir o tema da relação entre o candomblé e a saúde mental e iniciar o questionamento sobre a experiência pessoal do entrevistado, possibilitando o desvelamento de uma protonarrativa de iniciação e/ou chegada ao terreiro. As entrevistas foram transcritas integralmente e submetidas à análise de conteúdo, tal como pensada por Bardin ${ }^{27}$. O referido método mostra-se como um conjunto sistemático de técnicas e procedimentos que considera aspectos quantitativos do conteúdo em análise e, no entanto, não se atém a eles. Nesse sentido, também considera os conteúdos seja em sua literalidade, seja nos seus elementos de caráter mais implícito ou ambíguo (p. ex. figuras de linguagem, silenciamentos, incoerências e mudanças abruptas de assunto) ${ }^{28}$.

\section{Resultados e discussão}

\section{Trilhas, possibilidades e apropriações de um sofrimento sem nome}

É notável o caráter de criação identitária do grupo por meio do estandarte do sofrimento. Chegar doente ao candomblé é encontrar-se entre pares, é ser mais um à procura de cuidado, o que provavelmente contribuiu para a construção de relações mais empáticas: "No meu caso, foi por causa de doença, mas nem todo mundo entra por doença, né? Embora a maioria entre porque tem algum problema. São poucas as pessoas que eu conheço, uma ou duas na vida, que entrou porque achou bonito e queria cuidar do orixá. Mesmo assim, eu acho que devia ter algum probleminha que a pessoa não quis dizer, queria ser diferente." (E4); "Todo mundo vai para o candomblé com problema, é impressionante! Nunca vi coisa igual. [...] Todas estas [minhas] doenças, eu acho que são uma coisa só, que eu não sei que nome pode dar." (E7); "É, outros que caíam no meio da rua, que tinham essa história da crise de ausência... A gente já conhece mais ou menos a história. [...] Lá [terreiro] a maioria chegou por descaminhos, sabe, por doença também, né? Algumas pessoas que chegaram lá doentes, pra fazer um ebóii e aí chegaram lá e aí foram soldando, ficando.” (E8).

Apreende-se, todavia, que a chegada ao candomblé costuma ser um ponto final em uma longa trajetória de busca por cuidado em consultórios médicos e serviços de saúde, tal como se pode ver nos trechos a seguir: "Acordar bem cedo pra pegar número, pra marcar um exame que você ia fazer um mês depois, isso e aquilo. Então, foi bem cansativo. E quando tinha, quando tinha os desmaios, era UPA [Unidade de Pronto Atendimento], UPA, UPA. O pessoal da UPA de Marechal já até estranhava quando eu ficava muito tempo sem aparecer.” (E2); "[...] fiquei pulando de galho em galho, em vários psiquiatras. Todos me davam Rivotril e me mandavam pra casa. Eu falei: Alguma coisa tá errada... Porque isso não combina comigo, eu consigo fazer as coisas!" (E7).

Faz-se notar, inclusive, a premência de um tom quase prescritivo, nas entrevistas, da importância de recorrer primeiro às instâncias médicas do que às práticas ditas alternativas tradicionais dada a hipervalorização terapêutica e social da medicina biomédica. Isso vai, cabe dizer, na direção de outras pesquisas do campo que observam uma inversão de papéis entre a medicina tradicional e alternativa em grupos culturais específicos. Ao contrário do que se poderia supor a partir de uma inferência mais desatenta, a perspectiva médica raramente é ignorada e ocupa uma posição de destaque na fala de cuidadores religiosos e, por vezes, aparece na fala de pacientes que recorrem a eles de forma preponderante ${ }^{29}$.

No que diz respeito a esse ponto, a questão da comprovação da cura também se colocou. A emissão de laudos médicos, logo, a inserção da autoridade médica para comprovar a eficácia da terapêutica realizada

ii Espécie de ritual mais elementar de limpeza corporal e espiritual e que antecede todos os demais. 
no terreiro e a verificação empírica da cura ou remissão do sintoma também se fazem presentes. "Então, as pessoas chegavam lá todas estrupiadas, com n problemas! A gente tem relatos disso, documentou essas coisas. E as pessoas saíam curadas, pelo menos saíam e voltavam com raio X, com laudo.”(E8).

É interessante considerar aqui como o laudo emitido por um médico ganha novo propósito: tornase documento comprobatório da prática terapêutica desempenhada em um circuito cujo saber é alijado devido ao seu distanciamento do paradigma biomédico-científico. Esse exemplo evidencia de forma muito interessante as possibilidades de reconfiguração semântica de uma fonte de informação dentro de contextos com práticas infocomunicacionais específicas. Branco ${ }^{30}$ enfatiza o caráter social da informação no âmbito da saúde, ressaltando que a informação não se basta na assimilação, mas deve ser encarada, tanto sob o ponto de vista da forma quanto do conteúdo, na sua relação com o contexto político, econômico e sociocultural do interlocutor que é, antes de tudo, um agente no processo de construção informacional. Dito de outro modo, trata-se de enfatizar a impossibilidade de uma comunicação a-histórica ${ }^{31}$.

E é justamente nos meandros mediacionais que a informação sacramentada pelo registro profissional toma rumos surpreendentes e torna-se evidência do sagrado e de sua eficácia. Nesse sentido, a reapropriação do laudo ou atestado médico mostraria como não é possível tomar o dado ou informação em si mesmo. Se, por um lado, o laudo clínico poderia ser concebido apenas como um atestado ou documento emitido pelo detentor de um discurso específico e pensado como algo que deve ser compartilhado entre pares, por outro, a ressignificação sociocultural que se dá nesse processo evidencia que a informação não pode ser pensada apenas a partir de seus usos e finalidades preestabelecidos.

De acordo com Kleinman ${ }^{14}$, há uma concomitância na escolha e utilização dos diferentes sistemas terapêuticos disponíveis, que se mostram não-excludentes entre si na construção do itinerário terapêutico, podendo envolver espaços profanos e religiosos. Esse intermitente ciclo de aproximação e distinção entre os recursos dos diferentes sistemas aparece com força nos achados desta pesquisa, como se pode ver a seguir: "Pode se chegar num ponto, ou você vai fazer uma limpeza de corpo, né, um psiquiátrico também."(E3); "Na época em que eu fiz o santo, se eu fosse procurar um psicólogo, um psiquiatra, de repente eu não teria feito santo. Hoje eu já faria as duas coisas juntas." (E4); "E as doenças, é claro, se elas acontecerem, se elas apontarem e você correr para o candomblé e correr para o médico, eu tenho a impressão de que você vai estar pelos dois lados necessários, você vai estar apoiado, né?”(E11); “[...] Ele voltou a andar é, mas assim, pra que ele não tenha uma recaída e pare de andar de novo, ele continua no tratamento médico e continua no tratamento espiritual dele lá."(E11).

É possível apreender no conteúdo das entrevistas toda uma negociação envolvida no optar por determinadas terapêuticas ou não. Mais precisamente, parece haver um uso concomitante de vários tipos dentro dos recursos disponíveis. Assim, os sistemas de cuidado e suas práticas, na visão dos entrevistados, mostram-se menos opostos e mais complementares, no sentido de que pelas mãos da pessoa e da comunidade que o circunda vão sendo negociados e mais ou menos apropriados nesse complexo jogo do cuidado. Isso vai na contramão, porém, do pouco (ou em alguns casos nenhum) diálogo entre essas instâncias fornecedoras de cuidado. Atendo-se à relação entre os terreiros e os serviços de saúde do circuito dito oficial, percebese que, por vezes, a autoridade médica reconhece um diagnóstico espiritual e recomenda a recorrência a um espaço religioso: "Aí o médico falou: - Isso daí tem que ser alguém de santo pra ver o que ela tem, porque não é coisa de físico. Isso é coisa espiritual." (E3); "E até que ele falou pra mim em determinado momento, porque os surtos continuaram e aí ele falou: - Acho melhor você procurar ajuda, né? Aceitar ajuda espiritual." (E8).

Porém, isso pode vir a ocorrer de modo desinteressado ou como forma de encerrar a consulta com o feedback que pareceu possível: "Voltei novamente a pedir calmante. Ai eu falei com A.[médico]: A., eu preciso de alguma coisa! E A. rindo: Não, não sei o quê... Não, toma uma cerveja que isso passa. Eu falei: A., isso não tá passando, isso tá me atrapalhando! Ele: Não, vai procurar uma cartomante.”(E8). 
Pode-se questionar aqui qual seria a relevância de dizer a um paciente que sua questão tem a ver com "macumba" ou é "espiritual" sem abrir qualquer flanco de apoio ou acolhimento. Essa circunscrição da dimensão do sofrimento explicitado pelo paciente parece contribuir pouco para sua remissão ou diminuição. Mas, se por um lado, o embasamento em conhecimentos anátomo-fisiológicos fornece ao modelo biomédico uma posição dominante; por outro, o encontro da relação médico-paciente permitiria acessar outros modelos e conhecimentos gerados no seio de grupos sociais que se dirigem ao serviço de saúde $^{32}$. É explicitado, todavia, que esse caminho não é óbvio, tampouco evidente. A apropriação desses modelos por parte do profissional de saúde no processo de construção do projeto terapêutico é bastante prejudicada. "Você não vê o psiquiatra, que ele esteja preparado pra entender isso aí, sabe, conversar, pra ver realmente até que ponto é um distúrbio, até que ponto é uma questão da espiritualidade. [...] Pode não existir numa interpretação dele, mas pra aquele outro existe, é real. [...] De repente se [ele] tivesse tido esse entendimento, as coisas teriam sido mais fáceis pra mim". (E8).

A entrevistada aqui fala sobre a tênue fronteira entre a doença mental e espiritual e como esta, que ela percebe tão claramente, é negada pelos médicos, os quais por vezes se atêm aos seus próprios modelos explicativos e sem abertura para aqueles trazidos pelos usuários.

Não se pode deixar de lado, porém, a consideração de que a religião é capaz de dar um sentido à doença, à cura e à saúde, o que aponta para a complementaridade existente entre religião e medicina e, mais do que isso, pode-se perceber que os diversos atores sociais envolvidos frequentemente acabam por conferir à segunda uma supremacia sobre a primeira, no sentido de buscar um referencial mágico-religioso como explicação para a doença. Os diagnósticos apresentam-se, por conseguinte, indissociados da cosmologia e da concepção mágico-religiosa, refletindo o conjunto de relações sociais e os princípios básicos desse universo $^{33}$. A necessidade de valorizar esses modelos enquanto saberes é o que viria a permitir a construção de um terceiro conhecimento ${ }^{20-21}$.

Parece importante, portanto, que esses outros saberes sejam convocados a trazer suas contribuições, sejam elas oriundas de saberes acadêmicos, como aqueles das ciências humanas, ou daqueles por vezes denominados tradicionais ou folk, entre os quais se encontram aqueles de cunho religioso, mítico e da medicina popularit.

\section{A construção (compartilhada) de conhecimento na relação médico-paciente}

O encontro com o profissional de saúde, em especial com a figura do médico, mostra-se atravessado por complexas interconexões entre as expectativas daquele que chega ao serviço, a construção da demanda e a delimitação do potencial elenco a ser convocado a partir daí. A visualização desse amplo espaço vazio a ser preenchido por atores, cenários e roteiros, porém, por vezes mostrou-se aos entrevistados menos como um flanco de negociação e abertura para a construção de um projeto terapêutico do que como motivo de angústia diante de uma experiência de desamparo. Duas situações mostram-se de grande riqueza para a compreensão. Analisar-se-á cada uma delas neste momento.

A primeira delas diz respeito à falta de diagnóstico, apropriado por alguns dos entrevistados como "não ter nada": "Mãezinha, sua filha não tem nada. [...] Aí os médicos diziam: Ah! Isso é assim mesmo, nessa idade". (E2); "É, meu médico disse que eu não tinha nada." (E9); "Em todos os lugares que eu ia, as pessoas diziam que eu não tinha problema algum. Problema fisiológico... Patológico... Sei lá como é o nome desse treco... Doença, que eu não tinha nenhuma doença!" (E7); "Ele só falou: Você é normal, completamente normal." (E8);

"Fui ao médico. Na época fiz tomografia, não deu nada." (E1o); "O médico que falou pra mim, que organicamente ela não tem nada. Volta pra casa com ela... [...] Ela voltou até desmaiada pra casa”. (E3). 
Nas falas acima, observa-se que "não ter nada" delimita a finalização do encontro clínico de forma literal, funcionando como uma espécie de xeque-mate sem vencedores e desvantajoso para ambos os lados. Para o médico, que mesmo em posse de seu saber e de sua experiência profissional, abre mão de sua posição; mas também e, sobretudo, para aquele que vai até ele buscar cuidado ou tratamento e que sai sem respostas ou perspectivas. Faz-se notar aqui uma ênfase no diagnóstico e não no sofrimento experimentado e manifesto (ou não) pelo paciente. Ou seja, se "não ter nada" emerge como uma finalização do encontro médicopaciente, "ter alguma coisa" é poder dispor da relação e do arsenal médico-clínico. Residiria aí, portanto, o já malfadado olhar centrado na doença - que seria o fim último da odisseia diagnóstica - e que invisibiliza o indivíduo, cuja consideração passa a ser fragmentada ${ }^{34}$.

"Não ter nada", assim, encerraria o espaço de fala e elaboração de saberes, bem como isentaria o médico de se corresponsabilizar naquele encontro e diante do sofrimento do outro. Em outros termos, o sofrimento inverificável pelo aparato para diagnóstico médico passa a ser visto como uma queixa sem fundamento e, portanto, sem necessidade de maior atenção.

A segunda exclusão da possibilidade de intervenção médica concerne à experiência de "ser ou estar desenganado". Designa-se com essa expressão todos aqueles quadros diante dos quais foi feito o atestado de morte iminente e de impossibilidade de melhora, mesmo com a realização de qualquer procedimento médico. O material empírico evidenciou ser essa uma experiência frequente, apesar de sua singularidade, e que abre portas para a busca praticamente desesperada por qualquer outro recurso terapêutico que possa vir a salvar a vida em fenecimento. "Meu coração também começou a apresentar uns problemas e eu fui ao médico e o médico tinha me dado seis meses de vida. [...] Ele disse que tinha feito uns exames e que eu tinha um problema de nascimento. Que meu coração não ia resistir, que eu ia ter taquicardia e que seria uma coisa meio fulminante." (E1); "Os médicos me desenganaram pra ela. Ejá que pela parte de ciência nada foi feito, ela assinou um termo de responsabilidade, me levou para o barracão e me recolheu, onde foi feito o meu santo. [...] Eu acho que deu certo, porque hoje eu tenho trinta e cinco anos." (E9); "E aí quando a J. fez uns quatro meses, começou com uma diarreia e vômito que eu corria tudo quanto que era pediatra. [...] Eu peguei todos os exames de J. e levei pro PAM [Posto de Atendimento Médico] de Del Castilho. A mulher olhou, pediu outros exames que nem no PAM fazia. Fiz por fora. Aí ela falou: Olha só, eu não sei te dizer o que sua filha tem, mas posso te dizer que você deve se despedir dela. Falei: Como assim? É, da forma como sua filha tá evoluindo, ela não vai fazer um ano de idade. Ela não responde a nenhum tratamento. [...] Como é que você ouve isso de um médico, né?" (E8); "O médico virou pra ela [tia] e falou assim: Mãe, se você tem alguma maneira de orar, alguma crença religiosa, se apegue a ela, porque a gente não tá conseguindo mais fazer nada. A minha tia tirou a minha prima do hospital, com o hospital querendo processar e tal. E levou minha prima pra fazer santo. E minha prima já tá com vinte e quatro anos e não teve crise nenhuma." (E2).

Todos os trechos acima possuem uma estrutura semelhante: narram constatações médicas acerca da saúde (ou melhor, da falta de) de outrem a um parente próximo, que é informado antecipadamente da morte de seu ente querido. Todos os casos, com exceção de E1, deram-se nos primeiros dois anos de vida do doente, o que por certo inviabiliza um diálogo propriamente dito dele com o médico. O diálogo com o familiar, porém, em muito se aproxima daquele estabelecido com aqueles que "não tinham nada".

Nesses casos, o desengano não parece ter a ver com uma incompreensão das explicações médicas acerca de encaminhamentos, limites do uso de medicações ou de consequências do abandono do tratamento que faria o adoentado procurar por respostas em outro lugar ${ }^{35}$. Nos depoimentos citados, a sentença parece ter sido dada de modo bastante explícito ou mesmo condenatório.

Nesse sentido, o "não ter nada" e o desengano saem da negação do diagnóstico e chegam à sua máxima afirmação; afirmação esta imperativa e categórica de tal forma que, a partir do momento em que enunciada pela voz médica, se não nega o saber do paciente e de sua família, reduzem-no à esfera do que escapa ao 
conhecimento biomédico e que, portanto, não lhe compete. Devido a isso, encerram-se enquanto um fim em si mesmo.

O encontro com o profissional de saúde emerge aqui como algo que exigiria um certo trato específico, ou seja, o uso de determinadas expressões ou sinalizações que deem à sua fala possibilidade de reconhecimento, sem o qual torna-se complicada a gênese e investidura em um projeto terapêutico por ambas as partes. " $\mathrm{Eu}$ trabalhei muito tempo com médicos, né? Eu trabalhei numa ONG, que só ali tinha umas três pessoas que eram formadas em medicina. E também fiz análise. Fiz análise, uns dois, três anos. E fui à psiquiatra, tudo isso. Então, assim, a gente aprendeu a conversar com eles, né?” (E4).

Na visão de E4, médicos e psicólogos são pessoas com quem se precisa aprender a falar para ser tomado por eles como alguém que tem algo a dizer. Por esse raciocínio, para se "ter alguma coisa", ou seja, ser visto e nomeado como alguém que demanda cuidados, seria preciso dominar um determinado vocabulário que possa ser identificado pelo arcabouço teórico do profissional; seria necessário saber explicitar verbalmente aquilo de que se padece para poder, então, alçar o status de paciente.

Com relação ao primeiro momento de busca por atendimento em saúde, nota-se que este é bastante tortuoso, estando menos relacionado a uma escolha por opções ou possibilidades do que a um sentimento de escassez de recursos e suporte social. "Eu já não sabia mais o que fazer, na verdade eu não tinha mais norte, não sabia o que procurar." (E2); "Eu praticamente me senti assim... É... Abandonada, sem lugar pra ficar, sem lugar pra cuidar das minhas coisas, então eu fiquei em busca de um lugar!" (E5); "Eu fiquei muito na dúvida, não sabia o que fazer!" (E6); "Falei, caramba, tinha que ser alguém que pudesse chegar pra mim e falasse 'você é maluca mesmo entendeu?' ou dizer 'procura esse caminho, que é essa linha mesmo"." (E8).

Nas falas acima, contempla-se a inércia que caracterizou momentos específicos de seus itinerários terapêuticos. Um dos motivos subjacentes a isso é o fenômeno da porta giratória ou revolving door, conceito criado na psiquiatria, que consiste na quantidade de recaídas ou reinternações ocorridas em um serviço ao longo de um determinado período de tempo. Esse processo de idas e vindas constantes ao mesmo ou a outros serviços de saúde com fins de apaziguamento de um sintoma aparece, por exemplo, nas falas de E2: "Acordar bem cedo pra pegar número, pra marcar um exame que você ia fazer um mês depois, isso e aquilo. Então, foi bem cansativo. E quando tinha, quando tinha os desmaios, era UPA, UPA, UPA. O pessoal da UPA de Marechal já até estranhava quando eu ficava muito tempo sem aparecer." (E2).

No relato acima, fica patente que o fenômeno revolving door mostra-se como um indício de ineficácia terapêutica que contribui para que o usuário, principalmente aqueles com pouco ou nenhum acesso ao cuidado em saúde nem conhecimento das possibilidades de tal cuidado fique engessado em um itinerário limitado e ineficiente que não só não contribui para a melhora do quadro, mas pode mesmo ter efeitos antiterapêuticos ao mesmo tempo que gera estresse e desgaste físico e mental.

No caso de E2, o fenômeno da porta giratória combina-se com a ida a outros médicos de diversas especialidades que dizem não poder ajudá-la pelo fato de ela não possuir um diagnóstico propriamente dito, o que, como diz a própria entrevistada, delineou-se como um momento desgastante e cansativo. Talvez seja possível conectar a porta giratória à infertilidade dos recursos no próprio itinerário terapêutico, que, neste caso, se mostrou pobre em negociações e mediações entre os diferentes sistemas e dentro do próprio sistema. "Eu fui primeiro pro cardiologista. Depois eu fui pro ginecologista, por conta de contagem hormonal e tal, isso e aquilo. [...] O ginecologista disse que eu não tinha nada. Por conta das dores de cabeça, ele pediu pra eu procurar um neurologista. E aí o neurologista disse que eu não tinha nada. Pediu pra eu procurar um psicólogo ou um psiquiatra. O psicólogo analisou. Falou que eu não tinha nada [risos]. Foi um processo assim, bem longo. E bem chato." (E2).

Chama a atenção na fala de E2 o fato de que, em momento algum, os profissionais de saúde por ela procurados estabeleceram qualquer diálogo entre si, mesmo que a maioria dos profissionais que lhe 
atenderam seja conhecida de sua mãe, que também trabalha na área da saúde. E2 posteriormente fala que recebeu apenas encaminhamentos (sem um direcionamento específico, apenas para uma determinada especialidade) de cada um dos médicos, processo que foi concomitante às frequentes "visitas" à Unidade de Pronto Atendimento (UPA), onde também não obteve qualquer tipo de auxílio devido à inexistência de um diagnóstico. A problemática responsabilização faz-se notar também, na medida em que E2 segue uma rota entre vários especialistas que situam seu caso como algo a ser visto e tratado por outra expertise que não a sua.

É sabido que o encontro entre médico e paciente frequentemente abre pouco espaço dialógico acerca do conhecer e do intervir sobre a condição de adoecimento, na medida em que somente os elementos patognomônicos ou definidores para o estabelecimento do diagnóstico (tais como resultados de exames e relatos de sintomas da forma "mais objetiva possível", como é frequente se ouvir) são valorizados. Toda uma gama de apreensões, afetos e eventos podem ser negligenciados em nome de um formato de comunicação normativo, investigativo e informativo ${ }^{21,36}$.

Ao propor a valorização do cotidiano como lócus de criação e fruição do conhecimento, Freire ${ }^{37}$ permite pensar sua construção como algo coletivo, para além de fronteiras temporais e espaciais e com permanente abertura. Trata-se aqui, novamente, da gênese do terceiro conhecimento que ultrapassa o nível individual, visto que surge justamente na relação, e situa os sujeitos como protagonistas, rompendo com a unidirecionalidade do modelo verticalizante e silenciador voltado para a transmissão de conteúdos. Pode, com isso, efetivamente contribuir para mudanças nas condições de vida ${ }^{38}$. Por esse raciocínio, ao mesmo tempo que se estabelecem trocas com tamanho potencial de infusão e difusão, o encontro pacienteprofissional de saúde coloca-se como algo potencialmente transformador para ambos os lados.

A parca possibilidade de diálogo que aí se estabelece é algo conhecido no cotidiano daqueles que acorrem a algum serviço médico. Faz-se notar que, muitas vezes, as recorrências de pessoas a serviços de saúde não encontram no modelo biomédico categorias que deem conta de sua definição, fundamental para a construção de uma hipótese diagnóstica e de um projeto terapêutico. Isso se deve, em parte, ao fato de que por vezes não são reconhecidas lesões ou disfunções orgânicas subjacentes às queixas apresentadas.

O encontro terapêutico não pode se ater a uma relação prescritiva. A consideração de aspectos culturais e singulares concernentes à experiência de adoecimento, se importantes na relação médico-paciente de modo geral, ganham uma densidade ainda maior quando se trata de sofrimento difuso ${ }^{39-40}$ ou não diagnosticável do ponto de vista médico. Dessa maneira, é preciso olhar com atenção para como é desenvolvida essa abertura para a dimensão religiosa, pois "poderíamos questionar-nos se um paciente que seguisse uma doutrina espírita e estivesse reticente quanto à ingestão de um determinado medicamento, por acreditar ser o seu problema decorrente de um carma, estaria ou não sendo racional. E se o doente perguntasse ao seu psiquiatra se valeria ou não a pena encaminhá-lo a um terapeuta de vidas passadas? Embora tampouco possamos acusar o nosso psiquiatra de irracionalidade, qual seria o efeito terapêutico em responder: 'Veja, o que você tem é uma alteração do metabolismo de serotonina e precisa dessa medicação para se recuperar, caso contrário eu não vejo como ajudá-lo?” ${ }^{41}$.

Vislumbra-se aí, de todo modo, uma interação empobrecida ${ }^{42}$ e que desvaloriza o saber daquele que está justamente mais interessado na sua condição, qual seja, aquele que dela padece. Evidentemente, não se trata de promover uma reprovação do saber médico, tampouco de suas potenciais contribuições para a melhoria das condições de saúde e criação de novas trajetórias no processo saúde-doença em prol de uma hipertrofia do saber popular.

Ao propor uma sintonização de sistemas de crença entre médico e paciente baseada em Habermas, Nascimento ${ }^{41}$ enuncia como imprescindível a disposição por parte do médico a um entendimento mútuo, já que caberia a ele a função de intérprete, logo, de tradução e transdução entre as diferentes linguagens e saberes que perpassaram o diálogo com o paciente. Isso, evidentemente, implicaria alguns comprometimentos por sua parte, a saber: compartilhar, de forma inteligível e generosa, o conhecimento 
especializado concernente àquela consulta ou caso em especial, sair de uma postura impositiva calcada na autoridade médica e abertura para ouvir o sentido que os pacientes atribuem às suas experiências, por meio da valorização da narrativa.

Além disso, o autor ressalta que o sistema de crença do paciente possui coesão e coerências peculiares e relativas às conexões que se estabelecem entre tais crenças para aquele indivíduo em particular; de maneira que é preciso valorizar essas relações e abrir espaço para que elas sejam consideradas na pactuação do tratamento. Assim, a "sintonização de sistemas de crenças não se restringe à dimensão ética, mas seria também muito útil no sentido terapêutico: maior adesão ao tratamento, menor índice de abandono, melhor qualidade de vida para o doente, mais confiabilidade no médico e seguimento adequado das prescrições.”41

Ainda assim, percebe-se aqui um franco descompasso entre a abertura dos usuários às técnicas e serviços do sistema de saúde dito oficial e a desvalorização perpetrada pelos profissionais de saúde diante dos usuários que chegam a eles buscando por cuidado e tratamento. Nessa intrincada relação, "ser de santo"/adepto do candomblé pode vir a se mostrar como um cerceamento de possibilidades praticamente quando se está diante de alguma questão de saúde, dado que os profissionais frequentemente se isentam de responsabilidade - seja por desconhecimento, medo ou intolerância religiosa - quando se veem diante de um fenômeno sem diagnóstico biomédico no sentido estrito e/ou passível de compreensão a partir de leituras pautadas na liturgia de religiões de matrizes africanas.

\section{Considerações finais}

Diante do quadro aqui exposto, apreende-se que a população de terreiros de candomblé, tanto antes quanto depois do início de sua carreira religiosa, passa por diversos óbices quando procura serviços de saúde. Esses obstáculos, que possuem implicações clínicas e psíquicas, acabam também por repercutir no próprio processo de construção compartilhada de conhecimento que pode (e deve) se estabelecer no encontro clínico. Diante da ausência de um diagnóstico ou de recursos pautados nas acepções biomédicas acerca do cuidado, porém, pôde-se perceber a infertilidade dos itinerários nos serviços de saúde explicitada no fenômeno da porta giratória e na falta de acolhimento perceptível na fala dos entrevistados. Nesses casos, a relação médico-paciente não é nem mesmo informativa ou transmissional, visto que o profissional esvazia de conteúdo mesmo o seu espaço privilegiado de fala, deixando por vezes à própria sorte aquele que acorre ao serviço de saúde ou consultório. A ausência de diagnóstico, o diagnóstico espiritual ou mesmo a morte iminente confundem-se e ganham estatuto semelhantes na relação médico-paciente.

É preciso refletir sobre a abertura de flancos de diálogo entre profissionais de saúde e usuários, o que por certo passa pela necessidade de que a medicina ocidental também reconheça e se aproprie do saber religioso para melhor cuidar de seus pacientes ${ }^{43}$. Advoga-se, sobretudo, por um trabalho em rede que impõe a busca por novos espaços para a difusão, apropriação e gestão do conhecimento, entendido aqui como "um produto social distribuído, dotado de valor e que pode ser apropriado de diferentes formas sempre transformáveis" 44

Sendo assim, parece importante abrir condições de possibilidade para que essa dimensão da religiosidade e da espiritualidade seja abordada não como um diagnóstico, mas como um fator importante intrínseco à experiência de sofrimento e que, por isso, deve ser alvo de implicação e reconhecimento por parte do profissional de saúde. Isso não significa, evidentemente, a implementação de encaminhamentos para igrejas ou outros espaços religiosos, mas a discussão aberta com usuários acerca de sua vivência nesses locais, bem como a abertura para a troca com os atores que deles fazem parte, com vista ao incremento do projeto terapêutico delineado. 


\section{Referências}

1. Teixeira MLL. A encruzilhada do ser: representações da (lou)cura em terreiros de candomblé [thesis]. São Paulo: Universidade de São Paulo; 1994.

2. Vogel A, Mello MAS, Barros JFP. Galinha D'Angola: iniciação e identidade na cultura afro-brasileira. Rio de Janeiro: Pallas; 2007.

3. Gomberg E. Encontros terapêuticos no Terreiro de Candomblé Ilê Axé Opô Oxogum Ladê, Sergipe/Brasil. Salvador: Universidade Federal da Bahia; 2008.

4. Mota CS, Trad LAB. A gente vive pra cuidar da população: estratégias de cuidado e sentidos para a saúde, doença e cura em Terreiros de candomblé.Saúde. 2011; 20(2):325-337.

5. Bastide R. O Candomblé da Bahia: rito nagô. São Paulo: Companhia das Letras; 2005.

6. Gomes MCPA. Projeto: Ylê ayié yaya ilera (Saúde plena na casa desta existência): equidade e integralidade em saúde para a comunidade religiosa afro-brasileira. Botucatu:Interface; v.14 (34): p. 663-672, 2010.

7. Csordas TJ, Kleinman A. The therapeutic process. In: Johnson TM, Sargent CF, editors. Medical anthropology: a handbook of therapy and method. New York: Wesport; 1990. p.3-21.

8. Koenig HG. Religião, espiritualidade e psiquiatria: uma nova era na atenção à saúde mental. Rev Psiq Clín. 2007; 34 (1): 5-7.

9. Nascimento MC. De panacéia mística a especialidade médica: a acupuntura na visão da imprensa escrita. História, Ciências, Saúde - Manguinhos. 1998;1: 99-113.

10. Portugal CM. Da linguagem dos infortúnios às narrativas de doença: o sofrimento psíquico e a construção de itinerários terapêuticos entre adeptos do candomblé. Rio de Janeiro: Fundação Oswaldo Cruz; 2014.

11. Alves PC, Souza IM. Escolha e avaliação do tratamento para problemas de saúde: considerações sobre o itinerário terapêutico. In: Rabelo MC, Alves PC, Souza IM, editors. Experiência de doença e narrativa. Rio de Janeiro: Ed. Fiocruz; 1999. p.125-138.

12. Pinho PA., Pereira PPG. Itinerários terapêuticos: trajetórias entrecruzadas na busca por cuidados. Botucatu:Interface: 2012; 16(41): 435-50.

13. Young A. The creation of medical knowledge: some problems in interpretation. Social Science and Medicine. 1981; 15(9): 379-86.

14. Kleinman A. The illness narratives - suffering, healing and the human condition.New York: Basic Books; 1988.

15. Gerhardt TE. Itinerários terapêuticos em situações de pobreza: diversidade e pluralidade. Cad Saúde Pública. 2006; 22(11): 2449-2463.

16. Kleinman A. Patients and healers in the context of culture. Berkeley: University of California Press; 1980.

17. Kleinman A. Concepts and model for the comparison of medical systems as cultural systems. Social Science and Medicine. 1978; 12: 85-95.

18. Jeanneret $Y$. A relação entre mediação e uso no campo de pesquisa em informação e comunicação na França. Rev Eletr de Com Inf Inov Saúde. 2009; 3(3): 25-34.

19. Marteleto RM. Redes Sociais, medição e apropriação de informações: situando campos, objetos e conceitos na pesquisa em Ciência da Informação. Pesq. bras. Ci. Inf. 2010;3(1): p.27-46.

20. Marteleto RM. Informação, rede e redes sociais - fundamentos e transversalidades. Inf. Inf. 2007.

21. Marteleto RM, Valla VV. Informação e educação popular: o conhecimento social no campo da saúde. Per. em Ciência e Informação. 2003;(esp.):8-21.

22. Marteleto RM, Ribeiro LB, Guimarães C. Informação em movimento - Produção e organização do conhecimento nos espaços sociais. Civitas - Rev de Ciências Sociais. 2002;2(1): 69-80.

23. Carvalho MAP, Acioli S, Stotz EN. O processo de construção compartilhada do conhecimento: uma experiência de investigação do ponto de vista popular. In: Vasconcelos EM, editor. A saúde nas palavras e nos gestos: reflexões da rede popular e saúde. São Paulo: Hucitec; 2001. p. 101-144. 
24. Hudelson P. Qualitative Research for Health Programmes. Geneva: WHO, 1994. [cited 2013 feb 16]. Available from: http://libdoc.who.int/hq/1994/WHO MNH PSF 94.3.pdf

25. Fontanella BJB, Ricas J, Turato ER. Amostragem por saturação em pesquisas qualitativas em saúde: contribuições teóricas. Cad Saúde Pública. 2008; 24(1):17-27.

26. Groleau D, Young A, Kirmayer LJ. The McGill Illness Narrative Interview (MINI): An Interview Schedule to Elicit Meanings and Modes of Reasoning Related to Illness Experience. Transcultural Psychiatry. 2006;43(4):p. 671-691.

27. Bardin L. Análise de conteúdo. Lisboa: Edições 70; 1977.

28. Campos CJG. Método de análise de conteúdo: ferramenta para a análise de dados qualitativos no campo da saúde. Rev Bras Enferm. 2004;57(5): 611-4.

29. Csordas TJ. Meaning, healing and identity in Contemporary Navajo Society -Meaning, Healing and Identity in Contemporary Hungary [Internet]. [cited 2013 Oct 10]. Available from: http://www. colbud.hu/apc-aa/img upload/24ada9f1733ff0ecfd08ca674875c5b1/csordas 1.pdf

30. Branco MAF. Informação e Saúde. Rio de Janeiro: Editora Fiocruz; 2006.

31. Wolton DIECDCS. Culturels et politiques. Information et communication: dix chantiers scientifiques, culturels et politiques. E-Compós. 2005; 2: 2-14.

32. Jeanneret Y. Penser la trivialité: la vie triviale des êtres culturels. Paris Hermès Science. 2008;1.

33. Minayo MC. Saúde-doença: uma concepção popular da etiologia. Cad Saúde Pública. 1988;4(4).

34. Camargo Jr KR. A Biomedicina. Physis. 1997;7(1): 45-68.

35. Neves DP. As Curas Milagrosas e a Idealização da Ordem Social. Niterói: UFF; 1984.

36. Boltanski L. As classes sociais e o corpo. Rio de Janeiro: Graal; 1979.

37. Freire P. Pedagogia do Oprimido. 12th ed. Rio de Janeiro: Paz e Terra; 1983.

38. Marteleto RM, Nóbrega N, Morado D. Cultura informacional: demarcações de uma linha de estudos de cultura, informação e sociedade. In: Albagli S, editor. Fronteiras da ciência da informação. Brasília: IBICT; 2013. p. 78-106.

39. Valla VV. Educação popular, saúde comunitária e apoio social numa conjuntura de globalização. Cad de Saúde Pública. 1999;15 Suppl. 2:S7-14.

40. Valla VV. Redes sociais, poder e saúde à luz das classes populares numa conjuntura de crise. Interface. 2000;4(7): 37-56.

41. Nascimento ML. Em defesa de uma gestão compartilhada da medicação em psiquiatria. Physis. 2012;22(1): 275-290.

42. Favoreto CA. A Narrativa na e sobre a Clínica na Atenção Primária: uma reflexão sobre o modo de pensar e agir dirigido pelo diálogo, à integralidade e ao cuidado em saúde. Rio de Janeiro: Universidade do Estado do Rio de Janeiro; 2007.

43. Ally Y, Laher S. South African Muslim Faith Healers Perceptions of Mental Illness: Understanding, Aetiology and Treatment. Journal of Religion \& Health. 2008; 47(1):45-56.

44. Marteleto RM. Confronto simbólico, apropriação do conhecimento e produção de informação nas redes de movimentos sociais. DataGramaZero - Rev de Ciência da Informação. 2001; 2(1). 